\title{
Urgency of The Role of Parents Against The Use of Gadgets In Children of Primary Education
}

\author{
Istna Listiyani, Nurulfat Riani, Bening Brilianty Pamungkas \\ Universitas Sebelas Maret \\ listiyaniistna@gmail.com
}

\section{Article History}

accepted 24/09/2019

approved 01/10/2019

published 01/12/2019

\begin{abstract}
In the 21st century, the use of gadgets is increasing. Many advantages are offered with advances in increasingly sophisticated technology. It is not spared from that most of the use of gadgets is even misused by children of Primary Education age. Basically, the use of gadgets by minors starts from the family environment itself. If at the time the children are addicted to gadgets will cause growth retardation and other psychological disorders. This study aims to analyze the role of parents in the use of gadgets by Primary Education age children. The research method is a literature study. The results of the study are the role of parents as first and foremost educators for children is very important to control the use of gadgets in everyday life carried out by children. The conclusion of this research is the role of parents greatly influences the use of gadgets for Primary Education age children.
\end{abstract}

Keywords: parents, gadgets, children aged Primary Education

\begin{abstract}
Abstrak
Di era abad 21 penggunaan gadget semakin meningkat. Banyak keunggulan yang ditawarkan dengan kemajuan teknologi yang semakin canggih. Tidak luput dari itu kebanyakan penggunaan gadget malah disalahgunakan oleh kalangan anak usia Pendidikan Dasar. Pada dasarnya penggunaan gadget oleh anak di bawah umur berawal dari lingkungan keluarga itu sendiri. Jika pada masa anak-anak sudah kecanduan oleh gadget akan menimbulkan keterlambatan pertumbuhan maupun gangguan psikologis lainnya. Penelitian ini betujuan untuk menganalisis peran orangtua pada penggunaan gadget oleh anak usia Pendidikan Dasar. Metode penelitian yaitu studi pustaka. Hasil penelitian yaitu peran orang tua sebagai pendidik pertama dan utama bagi anak sangatlah penting untuk mengontrol penggunaan gadget dalam kehidupan sehari-hari yang dilakukan anak-anak. Kesimpulan penelitian ini yaitu peran orangtua sangat mempengaruhi penggunaan gadget untuk anak usia Pendidikan Dasar.
\end{abstract}

Kata kunci: orangtua, gadget, anak usia Pendidikan Dasar

Social, Humanities, and Education Studies (SHEs): Conference Series https://jurnal.uns.ac.id/shes

p-ISSN 2620-9284

e-ISSN 2620-9292 


\section{PENDAHULUAN}

Teknologi dan komunikasi berkembang saat ini sangat pesat dan canggih. Meningkatnya taraf kebutuhan masyarakat serta semakin besarnya tuntutan zaman mendukung pengembangan teknologi dan komunikasi dalam berbagai segi kehidupan di masyarakat. Gadget merupakan salahsatu bentuk nyata dari berkembangnya teknologi dan komunikasi pada zaman sekarang dan yang akan datang. Gadget adalah media yang dipakai sebagai alat komunikasi modernn dan semakin mempermudah kegiatan komunikasi manusia (Jati, 2014). Sedangkan menurut Sunita (2018) gadget adalah barang canggih yang diciptakan dengan berbagai aplikasi yang dapat menyajikan berbagai media berita, jejaring sosial, hobi, bahkan hiburan.

Sejak awal kemunculan gadget yang masih sederhana dan hanya digunakan untuk sebatas alat komunikasi, hingga kini menjadi kebutuhan primer dalam aktifitas sehari-hari manusia dan fungsi gadget semakin canggih pula.

Sekarang ini pengguna gadgetpun tidak hanya sebatas kalangan orangg dewasa, akan tetapi banyak anak-anak atau remaja sudah mampu mengenal teknologi dan komunikasi jenis ini untuk mempermudah aktifitas yang mereka lakukan setiap hari. Meningkatnya penggunaan gadget ini tentu akan sangat mempengaruhi pola kehidupan masyarakat baik dari segi polapikir maupun perilaku terutama bagi pengguna gadget yaitu siswa usia Pendidikan Dasar yang masih di kategorikan anakanak. Menurut Beichler dan Snowman (dalam Ramdhan Witarsa dkk, 2018) anak-anak memiliki pola pertumbuhan dan perkembangan dalam aspek fisik, kognitif, sosio emosional, kreatifitas, bahasa sertaa komunikasi yang khusus sesuai dengan tahapan yang sedang dilaluinya. Siswa usia Pendidikan Dasar tersebut cukup rentan akan pengaruh yang akan timbul akibat penggunaan gadget yang berlebihan dan tidak kenal waktu (lupa waktu).

Pada usia siswa usia Pendidikan Dasar mengalami perkembangan dalam tahap senang mengeksplor hal-hal yang baru didapat dan menarik perhatiannya melalui aktifitas bermain. Pada masa sekarang sudah hal biasa melihat siswa bermain dan memuaskan rasa senang dan penasarannya melalui gadget. Kenyataan tersebut disebabkan oleh beberapa kemungkinan situasi yaitu situasi pertama dimana ia belajar menggunakan gadget dengan mengamati orangtuanya yang setiap hari melakukan aktifitas melalui gadget atau karena situasi orangtua yang terlalu sibuk dengan pekerjaannya sehingga membiarkan anaknya meminta gadget dan memainkannya sendiri tanpa diberlakukannya aturan seperti mengatur waktu anak untuk belajar dan bermain gadget dengan benar.

Seiring berjalannya waktu, semakin meningkatnya rasa penasaran, kemampuan siswa tersebut dalam menggunakan gadget akan semakin membuatnya kecanduan apalagi ditambah dengan aplikasi-aplikasi canggih seperti aplikasi pemutar video atau youtube serta game online yang terdapat di dalam gadget, sehingga banyak dari mereka akan lebih tertarik bermain gadget hingga lupa waktu. Penggunaan gadget pada siswa usia Pendidikan Dasar tanpa adanya aturan dan pengawasan dengan benar dan tepat dari orangtua mereka dapat menimbulkan dampak-dampak yang tidak diinginkan seperti terganggunya pola pikir dan terhambatnya potensi yang miliki siswa itu sendiri.

Menurut Chusna (2017) Penggunaan gadget yang berlebihan akan berdampak buruk bagi anak. Anak yang menghabiskan waktunya dengan gadget akan lebih emosional, berontak karena merasa sedang di ganggu saat asyik bermain game. Malas mengerjakan rutinitas sehari-hari. Bahkan untuk makanpun harus di suapi, karena sedang asyik menggunakan gadgetnya. Sebenarnya gadget tidak hanya menimbulkan dampak negatif bagi anak, karena juga ada dampak positif, di antaranya dalam pola pikir anak yaitu mampu membantu anak dalam mengatur kecepatan bermainnya, mengolah strategi dalam permainan, dan membantu meningkatkan kemampuan otak kanan anak selama dalam pengawasan yang baik. Namun apabila 
tidak di sikapi dengan baik oleh orang tua, akan disayangkan apabila manfaat yang dapat diambil dari penggunaan gadget oleh anak akan kurang optimal dimanfaatkan.

Berdasarkan seminar pada tanggal 25 September tahun 2016 oleh Suwarsi (di dalam Chusna, 2017) ada beberapa perilaku anak terkait dengan gadget ini yang harus di waspadai oleh orang tua yaitu: a. Ketika ke asyikan dengan gadget anak jadi kehilangan minat dalam kegiatan lain. b. Anak tidak lagi suka bergaul atau bermain diluar rumah dengan teman sebaya. c. Anak cenderung bersikap membeladiri dan marah ketika ada upaya untuk mengurangi atau menghentikan penggunaan games. $d$. Anak berani berbohong atau mencuri-curi waktu untuk bermain gadget. Perilaku perilaku tersebut merupakan tanda bahwa mereka sedang memnbutuhkan bantuan dalam menghentikan aktifitasnya dengan kecanduan bermain gadget.

Menurut Sunita dan Mayasar (2018) tanpa di sadari anak sering menerapkan "What You See is What You Get" dimana penerapannya memiliki makna apa yang di lihat oleh anak adalah sebuah pelajaran, apabila tanpa bimbingan yang ter arah dan terpadu dari orang tua dan keluarga, perkembangan anak akan akan mengarah pada sisi negatif. Baik sisi positif maupun sisi negatif yang ditimbulkan dari penggunaan gadget, sangat penting bagi orang tua untuk memahami hal tersebut dan bagaimana dapat memanfaatkan dampat positifnya dengan baik serta mencegah atau mengantisipasi dampak negatif yang mungkin terjadi. Oleh karena itu, di perlukan pemahaman tentang pengaruh gadget terutama bagi orang tua agar anak dapat di batasi penggunaannya dan daya kembang anak dapat berkembang dengan baik dan menjadi anak yang aktif, cerdas, dan interaktif terhadap orang lain, membentuk sikap cekatan, melatih fokus, serta meningkatkan kecakapan dalam ber bahasa inggris.

Berdasarkan uraian di atas, selanjutnya di rumuskan masalah yaitu sebagai berikut: (1) Gadget di kalangan anak usia pendidikan dasar, (2) bahaya penggunaan gadget bagi anak usia Pendidikan Dasar, (3) peran orang tua terhadap pengunaan gaget yang berlebihan oleh anak usia Pendidikan Dasar. Dengan demikian, tujuan kajian ini yaitu untuk menjelaskan peran orang tua terhadap aktivitas anak, memaparkan bahaya penggunaan gadget bagi Sekolah Dasar, menganalisis peran orang tua terhadap pengunaan gaget yang berlebihan oleh anak usia Pendidikan Dasar.

\section{METODE}

Metode yang di gunakan dalam penelitian inii yaitu studi kepustakaan. Menurut Nazir (2003), mengemukakan bahwa "studi kepustakaan adalah teknik pengumpulan data dengan menggunakan studi penelaahanterhadap buku-buku, literatur-literatur, catatan-catatan, dan laporan-laporan yang ada hubungannya dengan masalah yang dipecahkan." Peneliti melakukan kajian yang berkaitan dengan teori terkait topik penelitian, mengumpulkan informasi sebanyak banyaknya dari kepustakaan yang saling berhubungan.

\section{Gadget di Kalangan Anak usia Pendidikan Dasar \\ HASIL DAN PEMBAHASAN}

Gadget yaitu istilah dalam bahasa Inggris yang berarti alat elektronik kecil dengan berbagai macam fungsi.Menurut Michael (dalam Harmanto: 2015), gadget lebih spesifik kepada instrumen kecil yang memiliki nilai guna tinggi, dengan contoh: HP, komputer, game dan masih banyak lagi.

Menurut Novia(2017) Anak-anak cenderung lebih suka bermain gadget sepanjang waktu dari pada bermain dengan temannya. Walaupun bertemu dan berpapasan di luar rumah, tetap saja HP masih ada digenggaman tangan.Sari(2016), menyatakan pada kalangan anak berusia pendidikan dasar mengunakan gadget hanya untuk bermain games dan hanya beberapa anak saja yang menggunakannya untuk menonton film kartun. Pada saat ini banyak anak yang kurang tertarik melihat televisi, 
karena saat ini sudah ada gadget yang dapat digunakan untuk apasja termasuk mencari informasi, Nurrachmawati(2014) menambahkan bahwa aplikasi yang terdapat dalam gadget tidak harus berisi pembelajaran saja, namun juga dapat berisi konten hiburan agar tidak terkesan jenuh.

\section{Bahaya Penggunaan Gadget Bagi Anak Usia Pendidikan Dasar}

Kemajuan teknologi diera abad ke 21 ini mengalami peningkatan yang sangat drastis. Pasalnya kebutuhan akan penggunaan gadget sangat diperlukan untuk mencari segala informasi. Penggunaan gadged sudah merambah keseluruh lapisan masyarakat, mulai dari anak hingga orang tua. Menurut Sari (2016) Pada dasarnya anak belum saatnya mengenal gadget. Pada masa pertumbuhan ini seharusnya anak bermain dan belajar secara menyenangkan untuk mendukung proses pertumbuhan dan perkembangan anak, baik fisik, kognitif, bahasa, sosial emosional dan moral.

Ketika penggunaan gadget digunakan secara berlebihan, secara tidak sadar seseorang sudah menabung banyak dampak negatif untuk diri sendiri maupun orang lain. Kurang dapat mengontrol emosi, acuh pada lingkungan sekitar, malas melakukan segala kegiatan, dan bersifat manja menjadi beberapa hal yang akan terjadi jika anak dibiarkan begitu saja dalam mengoperasikan gadget. Terbukti pada saat ini, generasi sekarang nilai moral, etika seperti menghormati orang yang lebih tua sudah menurun, tegur sapa dengan orang lain juga mulai luntur.

Menurut Sunita (2018), "terdapat beberapa perilaku yang harus diperhatikan orang tua ketika anak menggunakan gadget, yaitu:

a. Hilangnya minat dalam melakukan sebuah kegiatan karena asyik bermain gadget.

b. Anak menjadi anti sosial, sukar bergaul dan cenderung suka mengurung diri.

c. Anak akan marah jika diperingatkan untuk mengurangi penggunaan gadget dan cenderung membela diri.

d. Anak mulai berani berbohong untuk dapat bermain gadget dan mencuri-curi waktu.Perilaku tersebut menandakan bahwa anak sudah mulai kecanduan gadget. Meskipun dengan bermain gadget dapat menambah banyak kosa kata anak, namun ketika penggunaannya secara berlebihan akan kurang bermanfaat".

Menurut Suwarsi(2016) dari hasil seminar pengaruh gadget terhadap perkembangan anak, " sudah sewajarnya jika penggunaan gadget yang berlebihan akan menimbulkan dampak yang dapat dikatakan negatif bagi para penggunanya, diantaranya:

1. Waktu akan terbuang sia-sia

Anak akan lupa waktu ketika sedang asyik bermain gadget, mereka akan cenderung malas melakukan kegiatan lain. Sehingga pekerjaan yang harus diselesaikan hari ini malah tidak dikerjakan dan membuang waktu sia-sia. Padahal ketika kita memiliki waktu yang banyak secara tidak langsung akan mengembangkan keterampilan diri mengelola waktu.

2. Perkembangan otak yang terganggu

Ketika dalam keseharian, terlalu lama menggunakan gadget akan mengganggu perkembangan otak manusia. Sehingga dan mengakibatkan kemampuan berkomunikasi rendah serta kemampuan mengekspresikan pikiran sangat rendah

3. Banyaknya konten dan aplikasi yang tidak sesuai dengan tingkat usia anak SD, menurunnya nilai norma, edukasi dan agama.

4. Menganggu kesehatan

Semakin kita sering menggunakan gadget, akan berdampak pada kesehatan terutama mata. Dan juga akan mengurangi minat baca karena terbiasa pada objek menarik yaitu: bergambar dan bergerak.

5. Hilangnya ketertarikan pada aktifitas bermain atau melakukan kegiatan lain.

Gadget membuat anak lebih bersifat individualis atau menyendiri. Banyak contoh, ketika akhir pekan digunakan untuk bermain gadget sepuasnya daripada bermain dengan teman lain untuk sekedar bermain bola dilapangan". 


\section{Peran Orang Tua Terhadap Penggunaan Gadget Oleh Anak Usia Pendidikan Dasar}

Menurut Chusna (2017), penerapan aturan yang dilakukan oleh orang tua perlu digalangkan, supaya penggunaan gadget pada anak terkesan efektif. Orang tua dapat memberikan pemahaman mengenai konten-konten yang bermanfaat yang ada di gadget. Beberapa hal yang dapat dilakukan orang tua untuk mendisiplinkan anak dalam penggunaan gadget:

Pertama, orang tua mengenalkan dan mengawasi penggunaan gadget pada anak sejak dini.

Kedua, Hanya menginstal aplikasi yang sesuai kebutuhan anak yang dapat dikatakan aman. Selain itu orang tua harus menyesuaikan semua konten yang ada dalam gadget dengan usia anak. Orang tua harus lebih tau konten atau aplikasi yang dikuasai anak.

Ketiga, gadget ditempatkan di ruang umum/ruang tamu, sehingga kegiatan yang dilakukan anak dengan gadget dapat dipantau dengan mudah oleh orang tua.

Keempat, menerapkan aturan lama waktu penggunakan gadget pada anak. Walaupun secara realistis, gadget dapat meringkankan beban orang tua dalam mengurus anak(anak dibiarkan bermain gadget tanpa ada batasan waktu yang penting tidak mengganggu orang tua atau keluarga), namun dampak jangka panjangnya akan sangat merugikan baik itu secara fisik(tidak bisa berkembang selayaknya anak usia pendidikan dasar), psikologis(kurang bisa mengontrol diri), dan sikap(acuh terhadap lingkungan).Maka sebagai orang tua harus memberi contoh anaknya agar menaati aturan pengunaan gadget.

Kelima, orang tua berusaha membuat anak agar bisa membuat keputusannya sendiri. Beberapa hal yang dapat dilakukan untuk mendukung anak agar bisa membuat keputusannya sendiri, yaitu: selalu menanamkan rasa takut kepada Tuhan Yang Maha Esa, sehingga ketika akan berbuat kesalahan akan selalu ingat jika kita diawasi dan diperhatikan oleh Tuhan.

Sehingga pada penggunaan gadget yang berlebihan untuk anak berusia pendidikan dasar dapat dikatakan menghambat perkembangan otak, masalah kesehatan seperti mata bisa terganggu, menurunnya sikap moral anak seperti kurang peka terhadap lingkungan sekitar, dan akan menjauhkan orang-orang terdekat seperti keluarga, karena asyik bermain gadget.

\section{SIMPULAN}

Penggunaan gadget di kalangan anak usia Pendidikan Dasar banyak disalahgunakan, seperti penggunaan gadget yang melebihi batas waktu penggunaan gadget. Anak usia Pendidikan Dasar menjadi cenderung lebih suka menghabiskan waktu untuk bermain gadget daripada bermain bersama teman sebayanya.

Dampak yang timbul akibat terlalu sering menggunakan gadget yaitu: menghambat perkembangan otak, masalah kesehatan seperti mata bisa terganggu, menurunnya sikap moral anak seperti kurang peka terhadap lingkungan sekitar, dan akan menjauhkan orang-orang terdekat seperti keluarga, karena asyik bermain gadget.

Orang tua sangat berpengaruh terhadap anak dalam hal penggunaan gadget, orang tua menerapkan berbagai aturan guna mencegah penyalahgunaan gadget pada anak yang berusia pendidikan dasar, seperti diawasi ketika menggunakan gadget, memilih konten yang sesuai usia anak, mengatur durasi penggunaan gadget, merangkul anak untuk berdiskusi bersama agar tidak bermain gadget secara terus menerus.

\section{DAFTAR PUSTAKA}

Chusna, P.A. (2017). Pengaruh Media Gadget pada Perkembangan Karakter Anak. Jurnal STIT Al-Muslihun Vol. 17, No. 2. Blitar: STIT Al-Muslihun. 
Harmanto, B., dkk. (2015). Prosding Inovasi Pembelajaran untuk Pendidikan Berkemajuan. Jawa Timur: Universitas Muhammadiyah Ponorogo.

Jati, L \& Herawati, A. (2014). Segmentasi Mahasiswa Program Studi IImu Komunikasi Universitas Atma Jaya Yogyakarta (UAJY) dalam Menggunakan Gadget. Jurnal Universitas Atma Jaya Yogyakarta. Diakses dari http://ejournal.uajy.ac.id/5742/1/jurnal.pdf.

Nurrachmawati, (2014). Pengaruh Sistem Operasi Mobile Android pada Anak Usia Dini. Jurnal Pengaruh Sistem Operasi Mobile Android Pada Anak Usia Dini.. Makasar: Universitas Hasanuddin.

Prasetyaningsih, N., dkk. (2017). Penggunaan Gadget Pada Anak Usia Pendidikan Dasar di Jorong Laras Minang Nagari Kurnia Selatan Kecamatan Sungai Rumbai Kabupaten Dharmasraya. Sumatera Barat: STKIP PGRI.

Sari, P dan Mitsalia A. A. (2016). Pengaruh Penggunaan Gadget Terhadap Personal Sosial Anak Usia Pra Sekolah di TKIT Al Mukmin. Jurnal Profesi 13 (2) : 73 - 77.

Sunita, I \& Mayasari, E. (2018). Pengawasan Orangtua Terhadap Dampak Penggunaan Gadget pada Anak. Jurnal Kesehatan Masyarakat, STIKes AlInsyirah Pekanbaru halaman 510-514. Pekan Baru: STIKes Al-Insyirah.

Suwarsi. (2016). Hasil Seminar Pengaruh Gadget Terhadap Perkembangan Anak. Surabaya: Universitas Kristen Perta. 